\title{
Reliability of Apnea-Hypopnea Index Measured by a Home Bi-Level Pressure Support Ventilator Versus a Polysomnographic Assessment
}

\author{
Marjolaine Georges MD, Dan Adler MD, Olivier Contal PhD PT, Fabrice Espa RPSGT, \\ Stephen Perrig MD, Jean-Louis Pépin MD, and Jean-Paul Janssens MD
}

\begin{abstract}
BACKGROUND: Ventilators designed for home care provide clinicians with built-in software that records items such as compliance, leaks, average tidal volume, total ventilation, and indices of residual apnea and hypopnea. Recent studies have showed, however, an important variability between devices regarding reliability of data provided. In this study, we aimed to compare apneahypopnea indices $(\mathrm{AHI})$ provided by home ventilators $\left(\mathrm{AHI}_{\mathrm{NIV}}\right)$ versus data scored manually during polysomnography $\left(\mathrm{AHI}_{\mathrm{PSG}}\right)$ in subjects on noninvasive ventilation (NIV) for obesity-hypoventilation syndrome. METHODS: Stable subjects with obesity-hypoventilation syndrome on NIV, all using the same device, underwent 3 consecutive polysomnographic sleep studies with different backup breathing frequencies (spontaneous mode, low and high backup breathing frequencies). During each recording, $\mathrm{AHI}_{\mathrm{NIV}}$ was compared with $\mathrm{AHI}_{\mathrm{PSG}}$. RESULTS: Ten subjects (30 polysomnogram tracings) were analyzed. For each backup breathing frequency (spontaneous mode, low and high backup breathing frequencies), AHI values were $62 \pm 7 / \mathrm{h}, 26 \pm 7 / \mathrm{h}$, and $17 \pm 5 / \mathrm{h}$ (mean $\pm \mathrm{SD}$ ), respectively. Correlation between $\mathrm{AHI}_{\mathrm{NIV}}$ and $\mathrm{AHI}_{\mathrm{PSG}}$ was highly significant $\left(\mathrm{r}^{2}=0.89\right.$, $P<.001)$. As determined by Bland-Altman analysis, mean bias was 6.5 events/h, and limits of agreement were $+\mathbf{2 6 . 0}$ and $\mathbf{- 1 2 . 9}$ events/h. Bias increased significantly with higher AHI values. Using a threshold AHI value of 10/h to define appropriate control of respiratory events, the ventilator software had a sensitivity of $90.9 \%$, a specificity and positive predictive value of $100 \%$, and a negative predictive value of $71 \%$. CONCLUSIONS: In stable subjects with obesity-hypoventilation syndrome, the home ventilator software tested was appropriate for determining if control of respiratory events was satisfactory on NIV or if further testing or adjustment of ventilator settings was required. (ClinicalTrials.gov registration NCT01130090.) Key words: apnea-hypopnea index; noninvasive ventilation; monitoring; obesity-hypoventilation syndrome; home ventilator software. [Respir Care 2015;60(7):1051-1056. @ 2015 Daedalus Enterprises]
\end{abstract}

\section{Introduction}

Home noninvasive ventilation (NIV) is recognized as an effective treatment for chronic hypercapnic respiratory failure, and the number of patients using NIV devices is

Drs Georges, Adler, Contal, and Janssens are affiliated with the Division of Pulmonary Diseases, Department of Medical Specialties, and Mr Espa and Drs Perrig and Pépin are affiliated with the Sleep Laboratory, Department of Psychiatry, Geneva University Hospitals, Geneva, Switzerland. Dr Pépin is also affiliated with the Sleep Laboratory, University Hospital, and Université Grenoble Alpes, Grenoble, France.

This work was supported by unrestricted grants from the Pulmonary League of Geneva, the Swiss Society of Pulmonology, and the Lancardis continuously increasing. ${ }^{1,2}$ In many western countries, obesity-hypoventilation syndrome has become the leading indication for home NIV. In $\sim 90 \%$ of cases, obesity-hypoventilation syndrome is associated with obstructive sleep apnea syndrome, and NIV is used in these patients to

\footnotetext{
Foundation. The sponsors had no role in the protocol design, data analysis, or conception and writing of the manuscript. The authors have disclosed no conflicts of interest.

Correspondence: Jean-Paul Janssens MD, Division of Pulmonary Diseases, Department of Medical Specialties, Geneva University Hospitals, 4-6 Rue Gabrielle-Perret-Gentil, 1211 Geneva 14, Switzerland. E-mail: jean-paul.janssens@hcuge.ch.
}

DOI: $10.4187 /$ respcare.03633 
correct nocturnal hypoventilation and apneas or hypopneas. ${ }^{3-6}$ Clinical studies have shown that stable subjects treated with NIV on a long-term basis may have paucisymptomatic or asymptomatic residual respiratory events, which may compromise the benefit of NIV.7,8 Subtle changes in ventilatory parameters may also result in unwanted respiratory events. ${ }^{9}, 10$ Expert groups have emphasized the importance of appropriate monitoring of patients treated with NIV to detect and correct undesired nocturnal respiratory events. ${ }^{11-13}$ Although the American Academy of Sleep Medicine recommends monitoring NIV by polysomnography, this is not technically possible in many countries because of issues such as cost and availability. ${ }^{11} \mathrm{~A}$ previous consensus suggests that monitoring of NIV should include at least medical history, daytime arterial blood gases, nocturnal pulse oximetry, and data provided by home ventilator software. ${ }^{13}$ Whenever possible, use of nocturnal capnography is also recommended.

Although home ventilators do record a considerable amount of information for clinicians, there are some doubts as to the validity and accuracy of at least part of the information provided. Compliance and pattern of use recorded by home ventilators are most probably reliable and clearly useful. In a bench study of one specific home ventilator, estimation of leaks and tidal volume $\left(\mathrm{V}_{\mathrm{T}}\right)$ was shown to be accurate. ${ }^{14}$ However, a bench study of 7 home ventilators questioned the validity of estimated $\mathrm{V}_{\mathrm{T}}$ (and thus total ventilation) and leaks with huge variations between brands. ${ }^{15}$ In this study, $\mathrm{V}_{\mathrm{T}}$ was systematically underestimated, and bias increased with increasing leaks. Furthermore, leaks were reported differently according to manufacturers, some including intentional leaks and some not, whereas one ventilator averaged leaks only during expiration. There were considerable differences in estimation of leaks, and in 4 of 7 devices, estimation of leaks was clearly unreliable. These conflicting results raise some concern as to the use of other parameters provided by home ventilators, such as percentage of insufflations triggered or cycled by the device and estimations of apneas and hypopneas.

Apneas and hypopneas have been provided by CPAP devices for many years. However, a previous consensus statement noted that, in obstructive sleep apnea syndrome, CPAP devices estimated apneas and hypopneas using different algorithms according to each manufacturer, with all definitions being different from American Academy of Sleep Medicine consensus definitions. ${ }^{16}$ Available studies show good agreement between apnea indices (AI) measured by CPAP devices and polysomnography, but much lower correlations for hypopnea indices (HI). ${ }^{17-22}$

To our knowledge, the validity and accuracy of apnea-hypopnea indices (AHI) provided by home bi-level pressure support ventilators have not been independently

\section{QUICK LOOK}

\section{Current knowledge}

Ventilators designed for home care provide clinicians with data from integral software that records compliance, leaks, average tidal volume, total ventilation, and indices of residual apnea and hypopnea. Recent studies have demonstrated important variability between devices regarding the reliability of data provided.

\section{What this paper contributes to our knowledge}

The reliability of the apnea-hypopnea index provided by ventilator software is sufficient for monitoring subjects on long-term noninvasive ventilation for obesityhypoventilation syndrome. The data also were successful in determining whether control of residual obstructive or central respiratory events during NIV is sufficient or further testing is required. Studies in other populations and with other devices are needed.

studied. The complexity of bi-level versus continuous positive pressure may add to the discrepancy between estimated and measured AHI in patients on NIV. Furthermore, apnea episodes are rare, and hypopnea episodes are more frequent, and this may add to a potential lack of agreement between AHI provided by home ventilators and values recorded by polygraphy or polysomnography.

In this study, stable subjects on NIV for obesity-hypoventilation syndrome underwent 3 consecutive polysomnogram recordings with different ventilator settings. Changes in backup breathing frequency led to marked changes in central and obstructive hypopneas and apneas, providing an excellent database for comparing data provided by home ventilators and those simultaneously measured by polysomnography. ${ }^{9}$ This comparison was among the end points prespecified in the study design (ClinicalTrials.gov registration NCT01130090). All subjects were equipped with the same NIV device for this study.

\section{Methods}

The flow chart, methods, and inclusion criteria for this study have been described in detail previously.9,23 Briefly, 10 subjects treated with home NIV using the same device for obesity-hypoventilation syndrome were recruited by the Division of Pulmonary Diseases of Geneva University Hospitals. Obesity-hypoventilation syndrome was defined as the association of morbid obesity (body mass index of $\left.>30 \mathrm{~kg} / \mathrm{m}^{2}\right)$ and daytime hypercapnia $\left(\mathrm{P}_{\mathrm{aCO}_{2}}>45 \mathrm{~mm} \mathrm{Hg}\right)$ without any other obstructive or restrictive pulmonary pathology.4,6,24 All subjects had begun home NIV after at 


\section{AHI Measured by Ventilator vs PSG}

least one episode of acute hypercapnic respiratory failure. All subjects were in stable condition at inclusion. Exclusion criteria were: $<18$ y of age, $\mathrm{FEV}_{1} / \mathrm{FVC}<0.70$, poor compliance, and hospitalization for an acute episode of cardiac and/or respiratory failure within the previous 3 months. The 10 subjects underwent 3 consecutive polysomnographic sleep studies on NIV with 3 different backup breathing frequencies in random order: (1) spontaneous mode without backup breathing frequency, (2) spontaneous-timed mode with low backup breathing frequency (backup rate set at 2 points below the average nocturnal breathing frequency recorded by the built-in software of the subject's home ventilator during the previous 2 weeks), and (3) spontaneous-timed mode with high backup breathing frequency (set at the 95th percentile of the average nocturnal breathing frequency). No other ventilatory parameters were modified during the 3 nights. All subjects used a VPAP III ST-A ventilator (ResMed, San Diego, California). The study protocol was approved by the Geneva University Hospitals ethics committee for medical research, and written informed consent was obtained for all subjects.

\section{Polysomnography, Ventilator Software, and Respiratory Events}

Polysomnogram recordings, all performed on NIV, included standard electroencephalography (7 electrodes: F4, F3, C3, C4, Cz, O1, O2), left and right electrooculography, and submental electromyography. Left and right anterior tibialis electromyography was used to detect leg movements, and a bipolar electrocardiograph was used for cardiac monitoring. Air flow (pneumotachograph), thoracic and abdominal movements (XactTrace respiratory inductive plethysmograph, Embla, Buffalo, New York), $\mathrm{S}_{\mathrm{pO}_{2}}$, body position, and video were simultaneously and continuously monitored (RemLogic 1.1, Embla).

Sleep and microarousals were scored manually according to American Academy of Sleep Medicine criteria. ${ }^{25}$ The following parameters were quantified: total sleep time, sleep efficiency ([total sleep time/total recording time] $\times 100$, expressed as a percentage), duration of each sleep stage, percentage of total sleep time, wake-after-sleep onset, microarousal index (microarousals/h), and sleep latency. Microarousals were defined as an abrupt shift in electroencephalography frequency, including alpha waves, theta waves, and/or frequencies $>16 \mathrm{~Hz}$ lasting at least $3 \mathrm{~s}$.

Respiratory events were scored when associated with a drop in $\mathrm{S}_{\mathrm{pO}_{2}}$ of at least $4 \%$ and/or a microarousal and classified in 3 previously defined groups ${ }^{9}$ : central, mixed, and obstructive events. Patient-ventilator asynchrony was quantified as reported by Guo et $\mathrm{al}^{8}$ as a percentage of total sleep time. Data recorded by ventilator software were downloaded after each polysomnogram recording (ResScan 4.1.0.0., ResMed), including mean and 95th percentile values for leaks, which have been shown to be reliable with the VPAP III ST-A device. ${ }^{9,14}$

\section{Statistical Analysis}

According to distribution of variables, data are expressed as mean $\pm \mathrm{SD}$ or median (interquartile range) when appropriate. Data analysis was performed using SPSS 20.0 (IBM, Armonk, New York). Correlation between polysomnographic and ventilator software variables was performed with the Pearson test. Bias and limits of agreement between AHI values obtained from polysomnography $\left(\mathrm{AHI}_{\mathrm{PSG}}\right)$ and ventilator software $\left(\mathrm{AHI}_{\mathrm{NIV}}\right)$ were calculated according to Bland and Altman. ${ }^{26}$ Using an arbitrary threshold level of 10/h for AHI, sensitivity, specificity, and negative and positive predictive values of data provided by ventilator software were calculated. Association between $\mathrm{AHI}_{\mathrm{PSG}}$ and $\mathrm{AHI}_{\mathrm{NIV}}$ was tested by the Fisher exact test. The Friedman test was used to determine whether results between the 3 ventilator modes tested were significantly different. The Pearson test was used to compute correlation between the oxygen desaturation index and indices provided by ventilator software (AHI, AI, and $\mathrm{HI}$ ). For all tests, $P<.05$ was considered significant.

\section{Results}

Ten subjects with a median age of $52(51-61) \mathrm{y}$ and a median body mass index of $46.8(45.6-54.4) \mathrm{kg} / \mathrm{m}^{2}$ on NIV for 19.5 (16-67) months were prospectively included between October 2008 and December 2010. Subjects had normal arterial blood gas values at inclusion: $\mathrm{P}_{\mathrm{aO}_{2}}$, $72.7 \pm 10.9 \mathrm{~mm} \mathrm{Hg} ; \mathrm{P}_{\mathrm{aCO}_{2}}, 41.3 \pm 5.6 \mathrm{~mm} \mathrm{Hg}$; and $\mathrm{pH}$, $7.44 \pm 0.03$. Pulmonary function test results were: $\mathrm{FEV}_{1}$, $87 \pm 23 \%$ of predicted; FVC, $86 \pm 22 \%$ of predicted; and $\mathrm{FEV}_{1} / \mathrm{FVC}, 100 \pm 1 \%$ of predicted. Baseline ventilator settings were: inspiratory positive airway pressure, $20.5 \pm 1.2 \mathrm{~cm} \mathrm{H}_{2} \mathrm{O}$ (range of 16-28); expiratory positive airway pressure, $9.2 \pm 0.6 \mathrm{~cm} \mathrm{H}_{2} \mathrm{O}$ (range of 7-12); and backup breathing frequency, $14 \pm 1.5$ cycles $/ \mathrm{min}$. All subjects but one were equipped with a full face mask. Changes in backup breathing frequencies were $11(10-12)$ for low backup breathing frequency and 21 (18-22) for high backup breathing frequency.

Twenty-seven paired tracings were compared ( 3 recordings could not be completely downloaded from home ventilators). Leaks were low on average $(19.0 \pm 3.1 \mathrm{~L} / \mathrm{min})$, as were periods with either patient-ventilator asynchrony or autotriggering. As shown in Table 1, residual respiratory events were mainly central in spontaneous mode and predominantly obstructive with both low and high backup breathing frequencies. 


\section{AHI Measured by Ventilator vs PSG}

Table 1. Results of Pulse Oximetry, Polysomnography, and Capnography and Data Provided by Ventilator Software During Recordings Performed in Spontaneous Mode (No Backup Breathing Frequency) and in Spontaneous-Timed Mode With Low and High Backup Breathing Frequencies

\begin{tabular}{|c|c|c|c|c|}
\hline & $\begin{array}{l}\text { No Backup } \\
\text { Breathing } \\
\text { Frequency }\end{array}$ & $\begin{array}{l}\text { Low Backup } \\
\text { Breathing } \\
\text { Frequency }\end{array}$ & $\begin{array}{l}\text { High } \\
\text { Backup } \\
\text { Breathing } \\
\text { Frequency }\end{array}$ & $P$ \\
\hline Mean nocturnal $\mathrm{S}_{\mathrm{pO}_{2}}, \%$ & $92.4 \pm 0.4$ & $92.1 \pm 0.4$ & $92.2 \pm 0.4$ & .58 \\
\hline Minimal nocturnal $\mathrm{S}_{\mathrm{pO}_{2}}, \%$ & $77.9 \pm 2.5$ & $80.4 \pm 2.3$ & $81.0 \pm 2.2$ & .59 \\
\hline Time spent with $\mathrm{S}_{\mathrm{pO}_{2}}$ at $<90 \%, \%$ & $14.7 \pm 3.5$ & $14.9 \pm 3.7$ & $11.0 \pm 3.7$ & .67 \\
\hline Mean nocturnal $\mathrm{P}_{\mathrm{tcCO}_{2}}, \mathrm{~mm} \mathrm{Hg}$ & $46.7 \pm 4.0$ & $45.1 \pm 2.1$ & $45.6 \pm 2.5$ & .12 \\
\hline Total sleep time, $\min$ & $403.2 \pm 77.7$ & $460.2 \pm 57.9$ & $391.3 \pm 97.1$ & .27 \\
\hline Sleep efficiency, \% & $71.1 \pm 13.6$ & $80.2 \pm 8.5$ & $66.5 \pm 18.3$ & .27 \\
\hline Wake-after-sleep onset, min & $142.7 \pm 77.4$ & $106.3 \pm 53.6$ & $148.0 \pm 97.1$ & .91 \\
\hline $\mathrm{N} 1$ sleep, $\%$ total sleep time & $17.0 \pm 7.3$ & $13.4 \pm 5.9$ & $14.4 \pm 3.7$ & .50 \\
\hline N2 sleep, \% total sleep time & $55.4 \pm 9.6$ & $54.8 \pm 11.1$ & $59.8 \pm 10.9$ & .27 \\
\hline Slow-wave sleep, $\%$ total sleep time & $9.3 \pm 6.9$ & $13.9 \pm 9.5$ & $12.6 \pm 8.8$ & .12 \\
\hline Rapid-eye-movement sleep, \% total sleep time & $18.8 \pm 3.8$ & $17.9 \pm 6.2$ & $13.1 \pm 6.7$ & .067 \\
\hline Patient-ventilator asynchrony, $\%$ total sleep time & $11(7-20)$ & $8(2-32)$ & $6(0-31)$ & .73 \\
\hline Leaks, L/min & $3.6(1.8-7.8)$ & $6(1.2-9)$ & $6(2.7-15.2)$ & 60 \\
\hline Oxygen desaturation index, $n / \mathrm{h}$ & $59.3 \pm 6.2$ & $29.9 \pm 6.1$ & $21.1 \pm 4.7$ & .002 \\
\hline Microarousal index, $n / \mathrm{h}$ & $9.4 \pm 2.5$ & $12.9 \pm 2.1$ & $17.3 \pm 1.8$ & .15 \\
\hline Central event index, $n / \mathrm{h}$ & $26.9 \pm 6.8$ & $2.6 \pm 1.2$ & $2.9 \pm 1.7$ & $<.001$ \\
\hline Mixed event index, $n / \mathrm{h}$ & $9.7 \pm 1.9$ & $0.6 \pm 0.3$ & $0.4 \pm 0.2$ & $<.001$ \\
\hline Obstructive event index, $n / \mathrm{h}$ & $25.6 \pm 4.7$ & $22.5 \pm 7.1$ & $13.4 \pm 5.1$ & .067 \\
\hline $\mathrm{AHI}_{\mathrm{PSG}}, n / \mathrm{h}$ & $62.3 \pm 7.2$ & $25.7 \pm 7.0$ & $16.7 \pm 5.2$ & .006 \\
\hline $\mathrm{AHI}_{\mathrm{NIV}}, n / \mathrm{h}$ & $51.9 \pm 4.1$ & $23.0 \pm 7.1$ & $13.4 \pm 3.5$ & .050 \\
\hline $\begin{array}{l}\text { Values are expressed as mean } \pm \mathrm{SD} \text { or median (interquartile rang } \\
\text { boldface. } \\
\mathrm{P}_{\mathrm{tcCO}} \text { = transcutaneously measured partial pressure of carbon dio } \\
\mathrm{AHI}_{\mathrm{PSG}}=\text { apnea-hypopnea index measured by polysomnography } \\
\mathrm{AHI}_{\mathrm{NIV}}=\text { apnea-hypopnea index reported by ventilator software }\end{array}$ & d are unintentional. & btained by the Frie & ificant $P$ values (< & \\
\hline
\end{tabular}

Figure 1 shows the correlation between $\mathrm{AHI}_{\mathrm{PSG}}$ and $\mathrm{AHI}_{\mathrm{NIV}}$. Values for $\mathrm{r}^{2}$ were: $0.89(P<.001)$ for all tracings, $0.74(P=.001)$ for tracings in spontaneous mode, $0.90(P<.001)$ for tracings with low backup breathing frequency, and $0.83(P<.001)$ for tracings with high backup breathing frequency. Correlations between the oxygen desaturation index obtained during polysomnography and indices obtained from ventilator software were: $\mathrm{r}^{2}=0.85(P<.001)$ for $\mathrm{AHI}_{\mathrm{NIV}}, \mathrm{r}^{2}=0.62(P<.001)$ for $\mathrm{AI}_{\mathrm{NIV}}$, and $\mathrm{r}^{2}=0.226(P=.12)$ for $\mathrm{HI}_{\mathrm{NIV}}$.

Figure 2 shows agreement between $\mathrm{AHI}_{\mathrm{PSG}}$ and $\mathrm{AHI}_{\mathrm{NIV}}$ according to Bland and Altman. ${ }^{26}$ Mean bias (d) was 6.5 events/h; limits of agreement $(\mathrm{d} \pm 2 \mathrm{SD})$ were +26.0 and -12.9 events/h. As shown, bias increased significantly as AHI values increased.

We considered arbitrarily that subjects with a residual AHI of $<10 / \mathrm{h}$ had an appropriate control of respiratory events. Based on this threshold, Table 2 shows sensitivity, specificity, and negative and positive predictive values for detection of an abnormally high residual $\mathrm{AHI}$ using $\mathrm{AHI}_{\mathrm{NIV}}$.

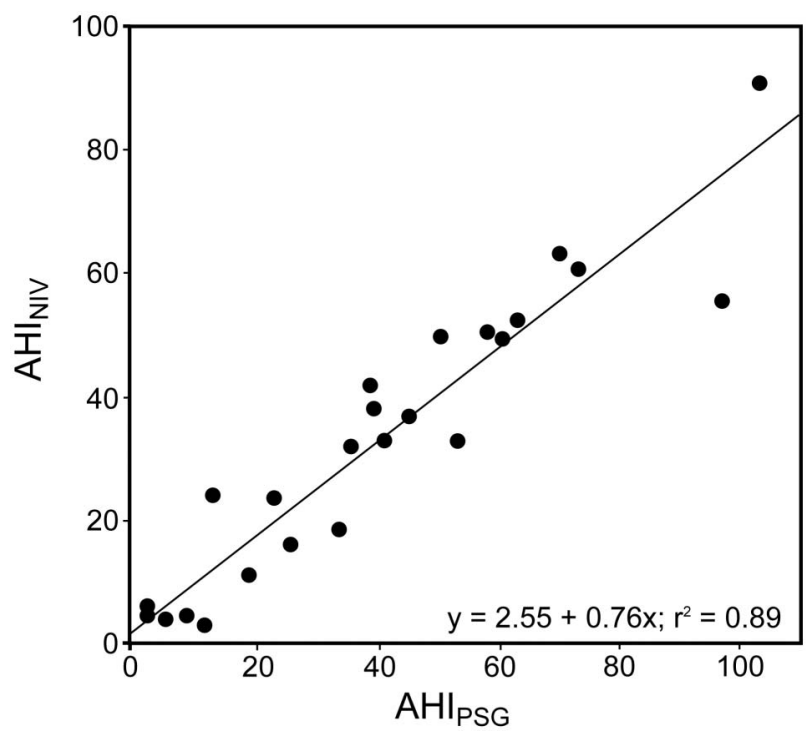

Fig. 1. Correlation between apnea-hypopnea index $(\mathrm{AHI})$ values scored manually during polysomnography $\left(\mathrm{AHI}_{\mathrm{PSG}}\right.$ ) and values obtained by ventilator software $\left(\mathrm{AHI}_{\mathrm{NIV}}\right)$. For all tracings, $\mathrm{r}^{2}=0.89$ $(P<.001)$. 


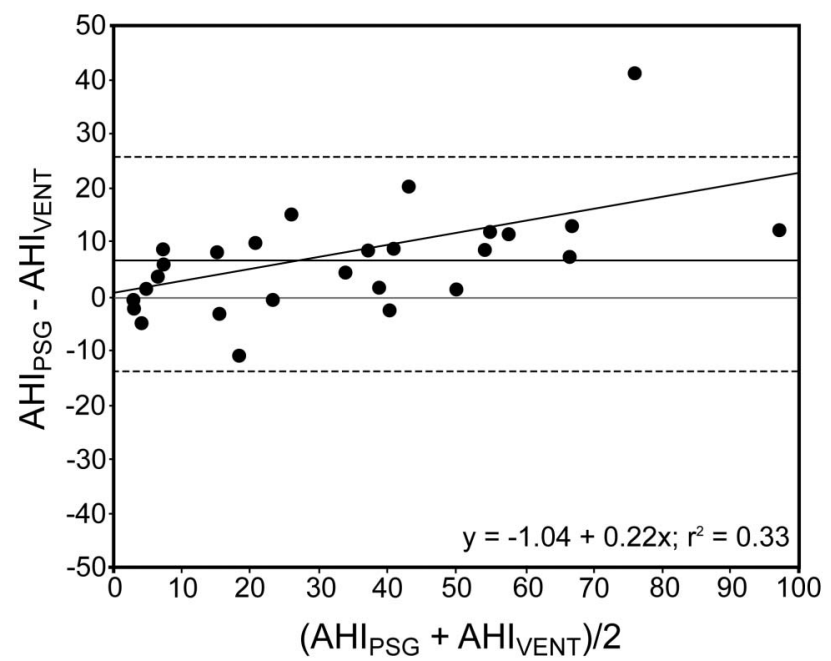

Fig. 2. Agreement between apnea-hypopnea index (AHI) values scored manually during polysomnography $\left(\mathrm{AHI}_{\mathrm{PSG}}\right)$ and values obtained by ventilator software ( $\left.\mathrm{AHI}_{\mathrm{NIV}}\right)$ according to Bland and Altman. ${ }^{26}$ Mean bias (horizontal black line) was 6.5 events/h; limits of agreement were +26.0 and -12.9 events/h $( \pm 2$ SD, dotted lines). As shown in the figure, bias increased significantly as $\mathrm{AHI}$ values increased.

Table 2. Sensitivity, Specificity, and Positive and Negative Predictive Values of Ventilator Software for Detection of Subjects With a Residual $\mathrm{AHI}_{\mathrm{PSG}}$ of $>10 / \mathrm{h}$

\begin{tabular}{lccr}
\hline \hline & $\mathrm{AHI}_{\mathrm{PSG}}>10$ & $\mathrm{AHI}_{\mathrm{PSG}}<10$ & Total \\
\hline $\mathrm{AHI}_{\mathrm{NIV}}>10 / \mathrm{h}$ & $20(74.1)$ & $0(0)$ & $20(74.1)$ \\
$\mathrm{AHI}_{\mathrm{NIV}}<10 / \mathrm{h}$ & $2(7.4)$ & $5(18.5)$ & $5(18.5)$ \\
Total & $22(81.5)$ & $5(18.5)$ & $27(100)$
\end{tabular}

Values in parentheses are the percentage of the total. $P<.001$ (chi-square test and Fischer exact test). Sensitivity, $90.9 \%$; specificity, $100 \%$; positive predictive value, $100 \%$; negative predictive value, 71.4\%; likelihood ratio of having an $\mathrm{AHI}_{\mathrm{PSG}}$ of $<10$ if $\mathrm{AHI}_{\mathrm{NIV}}$ is $<10$, 0.09 .

$\mathrm{AHI}_{\mathrm{PSG}}=$ apnea-hypopnea index determined by polysomnography

$\mathrm{AHI}_{\mathrm{NIV}}=$ apnea-hypopnea index determined by ventilator software

\section{Discussion}

To our knowledge, this is the first comparison of AHI provided by a home bi-level ventilator with those provided by simultaneous polysomnography with manually scored AHI. In a group of subjects on NIV for obesityhypoventilation syndrome, $\mathrm{AHI}_{\mathrm{NIV}}$ strongly correlated with $\mathrm{AHI}_{\mathrm{PSG}}$. Correlations between $\mathrm{AHI}_{\mathrm{PSG}}$ and $\mathrm{AHI} \mathrm{NIV}_{\mathrm{N}}$ were high with all 3 ventilation modes, irrespective of the fact that tracings in spontaneous mode included predominantly central events, whereas those performed with either a low or high backup breathing frequency included predominantly obstructive residual events. Bias (ie, mean difference between $\mathrm{AHI}_{\mathrm{PSG}}$ and $\mathrm{AHI}_{\mathrm{NIV}}$ ) was in a clinically acceptable range $(6.5 \pm 9.9$ events/h), increasing essentially with higher AHI values. However, when defining an arbitrary threshold value for a pathological residual
AHI ( $<10 / h)$, sensitivity, specificity, and positive and negative predictive values of AHI obtained by ventilator software were high. This suggests that AHI values obtained by ventilator software with the device tested allow the clinician to determine whether further testing is warranted (polygraphy, polysomnography) or whether central and/or obstructive respiratory events are adequately controlled by NIV.

During these sleep studies, unintentional leaks and patient-ventilator asynchrony were very low (see Table 1). This may be relevant because prolonged leaks and/or patient-ventilator asynchrony either induces or reflects a dissociation between the patient's spontaneous respiratory pattern and detection by the ventilator of the patient's efforts. ${ }^{10}$ Patient-ventilator asynchrony and leaks may thus affect the reliability of AHI provided by ventilator software, as well as that of other variables such as $\mathrm{V}_{\mathrm{T}}$, total ventilation, and percentage of cycles triggered and cycled by the patient. ${ }^{15}$ The clinician must thus be aware that the reliability of $\mathrm{AHI}_{\mathrm{NIV}}$ is (1) device-dependent and (2) can be adversely affected by leaks and/or patient-ventilator asynchrony.

The computation of $\mathrm{AHI}_{\mathrm{NIV}}$ remains somewhat mysterious for clinicians, and little information is provided by manufacturers. As for CPAP devices, it probably changes from one manufacturer to another and evolves with different generations of devices from a given manufacturer. ${ }^{16}$ Previous bench tests have shown to what extent performances and reliability of ventilator software can change from one device to another, and these discrepancies require regular independent testing. ${ }^{15,27}$

For this particular device, however, the present data substantiate the algorithm proposed by the SomnoNIV group, ${ }^{13}$ which states that medical history, daytime arterial blood gases, nocturnal pulse oximetry, and data downloaded using ventilator software suffice for regular monitoring of patients on long-term NIV.

This study has a few limitations. First, the number of recordings is modest. In our country and in many countries of Western Europe, polysomnography for patients on NIV is not routine, and the availability of polysomnography is limited, which explains the limited number of inclusions. Second, observations are limited to one type of ventilator. Similar studies should theoretically be performed either independently or provided by manufacturers to inform clinicians. Third, it is presently impossible for clinicians to analyze the agreement between events recorded by polygraphy or polysomnography and those recorded by ventilator software on an event-by-event basis, as ventilator software provides only an overall estimation of events for the entire night. The results presented thus reflect an approximation of the agreement between $\mathrm{AHI}_{\mathrm{PSG}}$ and $\mathrm{AHI}_{\mathrm{NIV}}$. An analysis of agreement event by event (ie, $\mathrm{AI}_{\mathrm{PSG}}$ vs $\mathrm{AHI}_{\mathrm{NIV}}$ and $\mathrm{HI}_{\mathrm{PSG}}$ vs $\mathrm{HI}_{\mathrm{NIV}}$ ) has yet to be per- 


\section{AHI Measured by Ventilator vs PSG}

formed. Finally, we lack information as to how ventilators report patient-ventilator asynchrony (whether unrewarded efforts or autotriggering affect $\mathrm{AHI}_{\mathrm{NIV}}$ ) and to what extent leaks affect $\mathrm{AHI}_{\mathrm{NIV}}$.

\section{Conclusions}

In summary, in spite of the abovementioned limitations, this study suggests that the reliability of AHI provided by ventilator software of the device tested is sufficient for monitoring subjects on long-term NIV for obesityhypoventilation syndrome and determining whether control of residual obstructive or central respiratory events during NIV is sufficient or if further testing (polygraphy, polysomnography) is required. Further studies are necessary to explore other devices and subjects with other indications for NIV.

\section{REFERENCES}

1. Janssens JP, Derivaz S, Breitenstein E, De Muralt B, Fitting JW, Chevrolet JC, Rochat T. Changing patterns in long-term noninvasive ventilation: a 7-year prospective study in the Geneva Lake area. Chest 2003;123(1):67-79.

2. Lloyd-Owen SJ, Donaldson GC, Ambrosino N, Escarabill J, Farre R, Fauroux B, et al. Patterns of home mechanical ventilation use in Europe: results from the Eurovent survey. Eur Respir J 2005;25(6): 1025-1031.

3. Borel JC, Tamisier R, Gonzalez-Bermejo J, Baguet JP, Monneret D, Arnol N, et al. Noninvasive ventilation in mild obesity hypoventilation syndrome: a randomized controlled trial. Chest 2012;141(3): 692-702.

4. Mokhlesi B. Obesity hypoventilation syndrome: a state-of-the-art review. Respir Care 2010;55(10):1347-1362; discussion 1363-1365.

5. Pépin JL, Borel JC, Janssens JP. Obesity hypoventilation syndrome: an underdiagnosed and undertreated condition. Am J Respir Crit Care Med 2012;186(12):1205-1207.

6. Piper AJ, Grunstein RR. Obesity hypoventilation syndrome: mechanisms and management. Am J Respir Crit Care Med 2011;183(3): 292-298.

7. Fanfulla F, Taurino AE, Lupo ND, Trentin R, D'Ambrosio C, Nava $\mathrm{S}$. Effect of sleep on patient/ventilator asynchrony in patients undergoing chronic non-invasive mechanical ventilation. Respir Med 2007; 101(8):1702-1707.

8. Guo YF, Sforza E, Janssens JP. Respiratory patterns during sleep in obesity-hypoventilation patients treated with nocturnal pressure support: a preliminary report. Chest 2007;131(4):1090-1099.

9. Contal O, Adler D, Borel JC, Espa F, Perrig S, Rodenstein D, et al. Impact of different backup respiratory rates on the efficacy of noninvasive positive pressure ventilation in obesity hypoventilation syndrome: a randomized trial. Chest 2013;143(1):37-46.

10. Rabec C, Rodenstein D, Leger P, Rouault S, Perrin C, GonzalezBermejo J. Ventilator modes and settings during non-invasive ventilation: effects on respiratory events and implications for their identification. Thorax 2011;66(2):170-178.

11. Berry RB, Chediak A, Brown LK, Finder J, Gozal D, Iber C, et al. Best clinical practices for the sleep center adjustment of noninvasive positive pressure ventilation (NPPV) in stable chronic alveolar hypoventilation syndromes. J Clin Sleep Med 2010;6(5):491-509.
12. Gonzalez-Bermejo J, Perrin C, Janssens JP, Pépin JL, Mroue G, Leger P, et al. Proposal for a systematic analysis of polygraphy or polysomnography for identifying and scoring abnormal events occurring during non-invasive ventilation. Thorax 2012;67(6):546-552.

13. Janssens JP, Borel JC, Pépin JL, SomnoNIV Group. Nocturnal monitoring of home non-invasive ventilation: the contribution of simple tools such as pulse oximetry, capnography, built-in ventilator software and autonomic markers of sleep fragmentation. Thorax 2011; 66(5):438-445.

14. Rabec C, Georges M, Kabeya NK, Baudouin N, Massin F, ReybetDegat $\mathrm{O}$, Camus P. Evaluating noninvasive ventilation using a monitoring system coupled to a ventilator: a bench-to-bedside study. Eur Respir J 2009;34(4):902-913.

15. Contal O, Vignaux L, Combescure C, Pépin JL, Jolliet P, Janssens JP. Monitoring of noninvasive ventilation by built-in software of home bilevel ventilators: a bench study. Chest 2012;141(2):469-476.

16. Schwab RJ, Badr SM, Epstein LJ, Gay PC, Gozal D, Kohler M, et al. An official American Thoracic Society statement: continuous positive airway pressure adherence tracking systems. The optimal monitoring strategies and outcome measures in adults. Am J Respir Crit Care Med 2013;188(5):613-620.

17. Berry RB, Kushida CA, Kryger MH, Soto-Calderon H, Staley B, Kuna ST. Respiratory event detection by a positive airway pressure device. Sleep 2012;35(3):361-367.

18. Cilli A, Uzun R, Bilge U. The accuracy of autotitrating CPAPdetermined residual apnea-hypopnea index. Sleep Breath 2013;17(1): 189-193.

19. Desai H, Patel A, Patel P, Grant BJ, Mador MJ. Accuracy of autotitrating CPAP to estimate the residual apnea-hypopnea index in patients with obstructive sleep apnea on treatment with autotitrating CPAP. Sleep Breath 2009;13(4):383-390.

20. Ikeda Y, Kasai T, Kawana F, Kasagi S, Takaya H, Ishiwata S, Narui K. Comparison between the apnea-hypopnea indices determined by the REMstar Auto M series and those determined by standard in-laboratory polysomnography in patients with obstructive sleep apnea. Intern Med 2012;51(20):2877-2885.

21. Prasad B, Carley DW, Herdegen JJ. Continuous positive airway pressure device-based automated detection of obstructive sleep apnea compared to standard laboratory polysomnography. Sleep Breath 2010;14(2):101-107.

22. Ueno K, Kasai T, Brewer G, Takaya H, Maeno K, Kasagi S, et al. Evaluation of the apnea-hypopnea index determined by the S8 autoCPAP, a continuous positive airway pressure device, in patients with obstructive sleep apnea-hypopnea syndrome. J Clin Sleep Med 2010; 6(2):146-151.

23. Adler D, Bridevaux PO, Contal O, Georges M, Dupuis-Lozeron E, Claudel E, et al. Pulse wave amplitude reduction: a surrogate marker of micro-arousals associated with respiratory events occurring under non-invasive ventilation? Respir Med 2013;107(12):2053-2060.

24. Hart N, Mandal S, Manuel A, Mokhlesi B, Pépin JL, Piper A, Stradling JR. Obesity hypoventilation syndrome: does the current definition need revisiting? Thorax 2014;69(1):83-84.

25. Iber C, Ancoli-Israel S, Chesson A. The AASM manual for the scoring of sleep and associated events: rules, terminology, and technical specifications, 1st edition. Westchester, IL: American Academy of Sleep Medicine; 2007.

26. Bland JM, Altman DG. Statistical methods for assessing agreement between two methods of clinical measurement. Lancet 1986;1(8476): 307-310.

27. Battisti A, Tassaux D, Janssens JP, Michotte JB, Jaber S, Jolliet P. Performance characteristics of 10 home mechanical ventilators in pressure-support mode: a comparative bench study. Chest 2005; 127(5):1784-1792. 